in places carious. The crucial ligaments were destroyed. The joint was flexed, but not dislocated. The other articulations in the body were normal. The left epididymis was converted into a caseous mass. The left testis was nearly wholly caseous, and in the centre was a collection of thick purulent fluid. The right epididymis was caseous, but the right testis appeared to be normal. Both the vesiculæ seminales were blocked with caseous matter. $\Lambda$ like material occupied a considerable part of the prostate. The bladder appeared to be in every respect normal. Both kidneys were studded throughout with miliary tubercles. The anterior parts of the bodies of the last two cervical and the first four dorsal vertebræ had been destroyed by caries, The inter-vertebral dises had also disappeared to an extent corresponding to that of the caries. There was no anterior abscess, nor, indeed, was any real pus found in the vicinity of the disease. There was no angular deformity of the column. The spinal canal opposite the affected dorsal vertebræ was occupied by a soft caseons mass. By means of this the cord had been compressed, and in this region it was found greatly softened. Both lungs were studded throughout with miliary tubercles. Here and there was a caseous mass. There were no cavities. There had been slight pleurisy (old) on one side. The peritoneum covering the stomach was dotted over with miliary nodules. It is remarkable that no other part of this membrane was affected. The brain and its membranes were normal, as were such viscera as have not been already referred to.

Clinical history.- The patient was a native of Windsor. His father and mother died when he was young, and he knew nothing of the causes of their deaths. Of four brothers one only is living. Of the other three, one died of a chest affection, one of fever, and a third of abscesses. He had never been strong, and had not been able to follow a definite employment. At the age of fourteen, when walking with bare feet, a rusty nail penetrated the left great toe. An abscess resulted and discharged. The parts did not heal, and at the end of four months the toe was amputated at the metacarpo-phalangeal joint. From this time the patient was never free from suppurative trouble. A few weeks after the operation an abscess formed in the palm of the left hand. Similar abscesses appeared at various parts of the body without intermission from this time. Before one healed another would appear, so that there were usually two present at one time. On admission there were two such abscesses, one on the dorsum of the right hand and one on the neck. They had all the characters ascribed to superficial tubercular abscesses. Before his death the abscess on the hand healed, but another appeared in the groin. Two years ago the patient began to be weak in the legs and to experience increasing difficulty in walking. There were no disturbances of sensation and no bladder or rectum troubles. He became an in-patient of St. Mary's Hospital, where he remained thirteen weeks. Blisters were applied over the dorsal spine, and he was sent out with a Sayre's jacket and a jury-mast. He left the hospital quite well. II wore the jacket for four months, and when he left it off he was able to work. The weakness of the legs had quite disappeared. He remained well in this respect until April, 1886, when the legs again commenced to feel weak. The weakness increased, and by July the patient had entirely lost all power in both lower limbs. At the same time he began to experience difficulty in retaining his fæces and urine.

When admitted into the London Hospital he was very thin, weak, and anæmic. There was complete loss of power in the lower limbs, but no loss of sensation. There was considerable loss of power in the right arm, but no anæsthesia. The patient had lost control over the sphincters. Large bedsores had formed over the sacrum. The right knee-joint was disorganised and filled with pus, and was flexed nearly at a right angle. A swelling had appeared in the left testicle six months previously, and another in the right testicle some three months before admission. Pain was complained of over the upper dorsal spinous processes. The column in this situation was rigid, and presented a trifling projection backwards.

The case admitted of none but general treacment. The patient became weaker and more emaciated. His temperature varied from $99^{\circ}$ to $103^{\circ}$. He was the subject of severe night sweats, but had no rigors. He suffered occasionally from diarrhoea. On Nov. 26 th he developed a slight cougb, which persisted until his death. IIe died of increasing debility on Dec. 5th.
Remarks by Mr. TReves, - Without entering upon the vexed question of the pathology of tuberculosis, the case presents certain notable clinical features. In a patient disposed to tubercular disease a simple injury may induce and localise the first manifestations of the trouble. From this primary centre the specific affection may slowly spread to other parts of the body, assuming the mode of progress of a very chronic type of pyæmia. It is allowed that in subjects predisposed to tuberculosis a simple lesion like catarrhal pneumonia may be the initial local factor in pulmonary phthisis. Rabbits appear to be naturally predisposed to tubercular processes, and in these animals the long retention of a simple seton may induce tubercular changes that in time become general and fatal. Moreover, if rabbits be made to breathe an atmosphere charged with atoms of the sputum from a tubercular patient (diffused by spray), and if their joints be contused, those articulations may become the seat of tubercular disease even when the lungs remain unaffected. In the present patient the mischief appears to have been induced by an injury to a toe, and I have no doubt that the subsequent changes in that part that led to amputation were of a tubercular nature. From this primary focus the trouble spread from one part to another. Certain of the superficial lesions underwent spontaneous cure. It is clear that the infection of the lungs, kidneys, and peritoneum were the latest phases of the disease. It is interesting to note that the vertebral affection remained quiescent for nearly two years. The knee became diseased after the onset of the paraplegia; it was never injured, and had long been retained in a position of complete rest. The occurrence of joint affections in limbs, the Eeat of nerre disturbances, is always a matter of interest. It may be surmised that the paraplegia served to localise the trouble in the knee, and that the relation between the affection in the cord and that in the joint was of a character allied to that assumed by many to exist in the case of Charcot's joint disease. It may be observed also that the weakness in the lower limbs had commenced on the right side, and was more marked in that extremity until the paraplegia became complete. One point remains: The diseased knee was flexed almost at a right angle. The knee disease had not commenced until the paraplegia was complete, and therefore the flexion must have been independent of muscular action. Its occurrence in a paralysed extremity serves to illustrate Braune's experiments of injecting fluid into the knees of post-mortem subjects. These experiments show that the flexed joint can accommodate more fluid than the extended one, and that distension of the cavity leads to flexion of the limb. The flexion in the present instance may be taken to represent that produced by distension alone, for the articulation was filled with pus.

\section{DEACONESSES' INSTITUTION AND HOSPITAL, TOTTENHAM.}

CEREBRAT FMBOLISMI FOLLOWING PARTURITION, TERMINATING IN H MIORRHAGE INTO LATERAI VENTRICLE ; NECROPSY.

(Under the care of Dr. Rusch.)

For the notes of the following case we are indebted to Mr. Lloyd G. Smith :-

C. C. - , aged thirty-three years, married, was admitted on Oct. 26th, 1886. She complains of weakness of the upper and lower extremities on the right side and giddiness, and is aphasic (of the amnesic type). The illness began two weeks and a half ago. Her father died of a "head affection"; several members of her family are " subject to fits." She is in comfortable circumstances, and of satisfactory habits. Four years ago she was burnt and frightened by the explosion of a fog-signal in the fire, which had got in among the coals; this laid her up for two months. Has had no previous illness. Her present illness began three weeks after ber last confinement (ninth), which took place five wetks before admission. The puerperium was quite normal, and lasted two weeks. After being up a few days, she fell while walking along the passage of the house (no known cause-supposed giddiness); was able to get up herself, and suffered no appurent ill effect, but in four days afterwards she had " the hands being clenched and the mouth drawn to the right side. $\Lambda$ streak of blood was seen on the lip. On recovery from the fit her right side was suid to have been para- 
lysed; the face on that side had improved since, while the aphasia remained stationary. Has had nine children; no miscarriages. Two children died, one of measies and one of bronchitis. Labours and puerperia always normal. No specific history.

On admission she had a heavy and vacant expression, but no paralysis of face. She was pale, and well developed, tending to obesity ; tongue protruded straight out, but with difficulty; bowels constipated; no abnormal physical signs in alimentary, respiratory, or circulatory systems. Temperature $100^{\circ}$; became normal afterwards. Pupils equal ; somewhat dilated; no strabismus. Organic reflexes normal. Patellar reflexes exaggerated on both sides. Slight ankle-clonus. Plantar reflex absent on right side; marked on left. The grasp of the two hands appears to be equally strong. Extremities of right side redder and of higher temperature than those of left. She attempts conversation, but is quite unable to express herself; uses words of few syllables only; time and quantity appear especially difficult to express, her attempts ending with "How stupid I am." Is unable to write her name, but begins first two letters correctly, and then says she "can't see." The case was diagnosed to be on $\theta$ of embolism in the middle cerebral artery or one of its branches, and the treatment was mainly expectant.

The patient's condition remained as above until Nov. 4th, when in the evening she became restless, imagined her child was dead at home, and was depressed and emotional; had a good night. On the morning of the $5 \mathrm{th}$, while taking breakfast, she became suddenly unconscious. The right side was limp and motionless, while the left hand was raised up to her face as if to wipe away something. Right eyeball insensitive. Left ocular reflex normal. Pupils equal at first ; later on, right dilated and left contracted. Two hours afterwards the patient became unconscious, the face dark and livid, and respiration ceased, the heart's pulsution continuing a few minutes longer.

Necropsy, seven hours after death.-Vessels of scalp and meninges very congested. Large clot distending the left lateral ventricle; an area the size of a walnut in the left third frontal convolution near the posterior part and in surrounding part of brain, softened into a red diffluent mass, with vessels passing through it. In the middle cerebral artery, at its origin, a large embolus was easily detected. There was effusion of lymph at the base of the brain. With the exception of a small blond cyst on the surface of the liver, all the organs (including the uterus) appeared healthy. No signs of atheroma were found.

\section{SOUTH DEVON AND EAST CORNWALL} HOSPITAL, PLYMOUTH.

REMOVAL OF THE UPPER EXTREMIITY, AND LATER OF THY SCAPULA AND PART OF THE CXAVICLE, FOR SARCOMA. (Under the care of Mr. Paur Swain.)

Fon the following notes we are indebted to Dr. Buchan, house-surgeon.

Louis $\mathbf{G}-\longrightarrow$, aged eighteen years, picture-frame maker, was admitted on Feb. 7th, 1886, for tumour of left shoulder. The patient was a pale, delicate lad, much emaciated, with an anxious expression. The family history and previous personal history were good. He complained that six months before admission he used to be frequently pinched in the left deltoid by a fellow-workman. About two months afterwards he first noticed pain and swelling over the deltoid. This swelling had increased rapidly during the following two months, with great increase of pain. On examination (Fig. 1) there was a large firm swelling involving the whole upper part of the left humerus, and extending somewhat over the scapula and clavicle. The humerus moved with the scapula, almost entirely. There were enlarged veins over the tumour, but no glands were involved.

On Feb. 11th, under methylene, a $\mathbf{V}$-shaped incision was made over the scapula, as if for excision of that bone. However, on cutting down to the joint, the humerus only was found to be involved, and it was removed at the joint All arteries were tied with chromic catgut, the wound dressed with iodoform and carbolic oil on lint, and a drainagetube inserted. Morphia and stimulants were freely used from the time of the operation. On the evening of the 12th the temperature was $101.2^{\circ} \mathrm{F}$, the highest point.
For the first fortnight the wound was dressed under the carbolic spray, by which time it was practically healed.

The patient was discharged cured on March 13th, and had no return of the disease. The tumour was a myeloid sarcoma, arising from the periosteum and causing erosion of the bone.

On April 22nd the patient was readmitted with a recur-

FIG. 1.

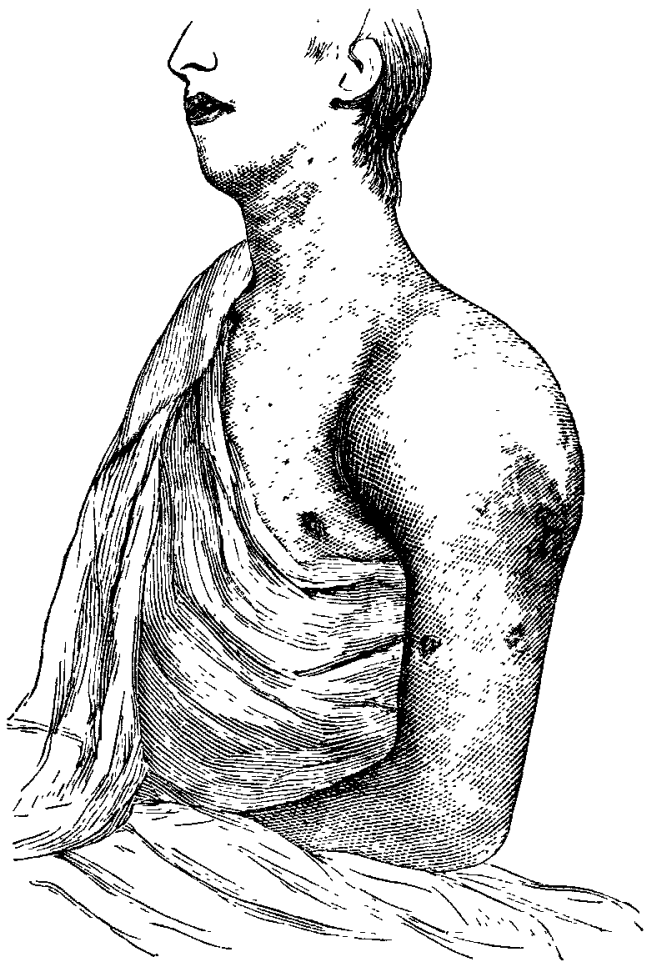

rence of growth in the left scapula. On April 24th, under methylene, a V-shaped flap was made over the scapula and the whole bone removed, together with the acromial end of the clavicle. Wound dressed as before. A slight skin slough formed at the lowest end of the flap, but with this exception the wound healed rapidly. The patient was discharged on May 27 th.

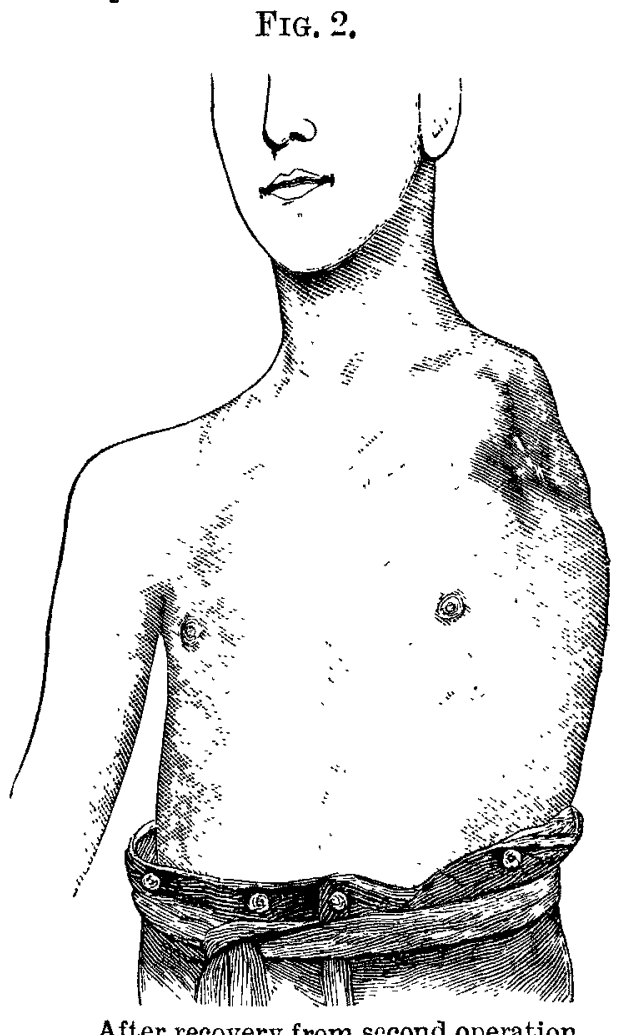

Remarks by Mr. PAUL SwaIn.-I regret to say that some weeks after his discharge from hospital the patient caught a severe chill while boating. Pneumonia of the right lung set in, and he gradually sank. (The woodcuts are from photographs kindly taken by Fleet-Surgeon Longfield H.M.S. Royal Adelaide). 